\title{
Sheep study calls for closer look at prion hypothesis
}

The infectious agent behind diseases such as mad cow, scrapie and variant Creutzfeld-Jakob disease may not necessarily be rogue prion proteins, say British researchers - a suggestion that flies in the face of current dogma about how these diseases are spread.

Although deformed prions are a characteristic of these diseases, they may not be the initial infectious agent, says lead researcher Martin Jeffrey of the Veterinary Laboratories AgencyLasswade near Edinburgh. The researchers are basing their theory on how these proteins are absorbed in the sheep gut.

In July 2005, the Medical Research Council

(MRC) announced a plan to relocate the prestigious National Institute for Medical Research (NIMR) from its home in suburban Mill Hill to London. The MRC has claimed that the move would foster more clinical research, primarily through collaboration with the University College London and its teaching hospital. The announcement came after months of acrimonious debate between the council and the institute's researchers (Nat. Med. 10, 762; 2004).

British intelligence and local politicians are now raising doubts about the MRC's plan to house the institute's level-4 containment facility on the eleventh floor of a new building in the heavily populated area.

According to a report in The Evening Standard, the UK's MI5 National Security Advice Centre has raised "grave concerns" about the potential release of dangerous

Plans to shift the UK's leading medical research institute to central London are under fire because the move would include he institute's facility for working with ngerous pathogens.
Experts contacted by Nature Medicine declined to comment on the controversial paper.

The scientists inoculated sheep intestines with brain extracts containing the abnormal form of the prion protein $(\mathrm{PrP})$, the hallmark of the killer neurodegenerative disease. But when they later examined the infected sheep, the rogue protein had congregated at entirely different sites ( $J$. Pathol. 209, 4-14; 2006).

"Despite the fact that the Nobel Prize was awarded for the prion hypothesis, there remains the possibility that it's not the correct explanation," says Jeffrey. "There needs to be a more assiduous investigation of the causes of this group of diseases."

The study also suggests that the mechanism of resistance against these diseases does not operate at the level of gut absorption, as some researchers had said. The 50 sheep studied displayed different levels of resistance to scrapie, but all absorbed the prions equally readily.

Although the study suggests that prion proteins can be absorbed by the gut, this seems to happen only rarely, at least in sheep. If the same is true of humans, then scientists may need to rethink exactly how the consumption of tainted meat leads to disease.
Jeffrey's team predigested a mixture of abnormal PrP and typical sheep stomach contents. But when they then injected this into the gut, almost no rogue protein was absorbed, and subsequent testing found that the mixture contained almost no abnormal PrP. Jeffrey says that sheep in the field are probably exposed to very little prion protein in their gut, because their stomachs would dispose of even the miniscule amounts ingested.

Another possibility is that absorption occurs higher in the gut, before proteins are digestedperhaps in the mouth, suggests Nicole Sales, who studies prion disease at the Scripps Research Institute in Jupiter, Florida.

If prions are not the infectious agent, the real culprit remains a mystery. "This experiment doesn't detect the infectious agent," says Jeffrey, but suggests that a fragment of the prion protein, perhaps too small to detect using standard detection methods, may be the guilty party.

The new discovery does not rule out the possibility that prion proteins, if absorbed in sufficient amounts, can also cause disease, Jeffrey says. But he contends that these proteins are not the whole story. "It's opening up a doorway into another biological paradigm," he says.

Michael Hopkin, London

\section{Security fears plague deadly disease lab's move to central London}

Don't be a sheep: People don't question the prion hypothesis enough, say pathogens, either through a terrorist attack on the building or during transportation to and from the facility. MI5 has to approve any plans for level-4 facilities.

Nick Winterton, the MRC's executive director, downplays the security concerns, saying the initial proposal is "a fairly broad-brush feasibility plan.” The MRC is considering several options including separating the level-4 facility from the institute's new location, he says.

But NIMR scientists say splitting the facility would seriously hamper research. "It would be grossly inefficient," says Jonathan Stoye, head of the institute's division of virology. Much of the research at the facility involves animals that must be monitored constantly, Stoye says. "You'd have people running backwards and forwards several times a day. I don't think you can run a facility on such a basis." An NIMR report last April strongly recommended including the lab in any relocation plans.

The facility-equivalent to a US biosafety level-4 lab - is one of only a handful in the UK and is being used almost exclusively for analyzing samples of flu virus from around the world. The lab is part of a World Health Organization network that works both on the H5N1 bird flu virus and more conventional strains included in each year's flu vaccine. But its focus is expected to expand to include other emerging diseases.

Winterton says it may be possible to relocate the lab and still address security concerns. "Many hospitals and universities in London have high-level containment facilities," he notes. The MRC may also consider other options, including using facilities already in the city or building a new lab on a separate site.

How easy it will be to move the lab may depend in large part on community response, says Edward Hammond, US director of the Sunshine Project, a nonprofit group that opposes biodefense research. Hammond notes that some facilities in the US have been stopped by local opposition, but openness may go a long way toward assuaging concerns. "Transparency must come above all," he says.

A final proposal on the lab is expected by October, and construction on the new NIMR is slated to begin in 2009.

Geoff Brumfiel, London 